\title{
8
}

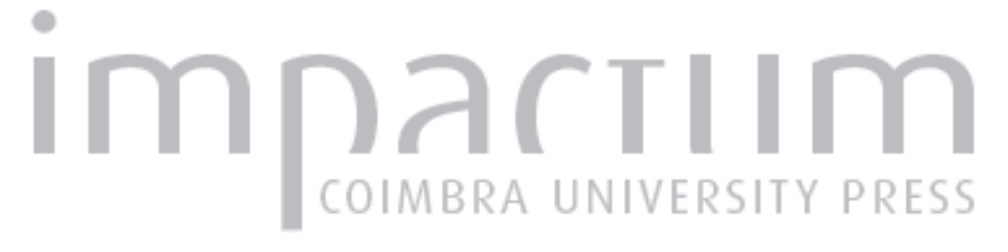

\section{Itália nos Ensaios de António Sérgio}

Autor(es): $\quad$ Miranda, José da Costa

Publicado por: Imprensa da Universidade de Coimbra

URL persistente:

URI:http://hdl.handle.net/10316.2/45048

DOI: DOI:https://doi.org/10.14195/2183-8925_5-1_9

Accessed : $\quad$ 26-Apr-2023 14:31:02

A navegação consulta e descarregamento dos títulos inseridos nas Bibliotecas Digitais UC Digitalis, UC Pombalina e UC Impactum, pressupõem a aceitação plena e sem reservas dos Termos e Condições de Uso destas Bibliotecas Digitais, disponíveis em https://digitalis.uc.pt/pt-pt/termos.

Conforme exposto nos referidos Termos e Condições de Uso, o descarregamento de títulos de acesso restrito requer uma licença válida de autorização devendo o utilizador aceder ao(s) documento(s) a partir de um endereço de IP da instituição detentora da supramencionada licença.

Ao utilizador é apenas permitido o descarregamento para uso pessoal, pelo que o emprego do(s) título(s) descarregado(s) para outro fim, designadamente comercial, carece de autorização do respetivo autor ou editor da obra.

Na medida em que todas as obras da UC Digitalis se encontram protegidas pelo Código do Direito de Autor e Direitos Conexos e demais legislação aplicável, toda a cópia, parcial ou total, deste documento, nos casos em que é legalmente admitida, deverá conter ou fazer-se acompanhar por este aviso.

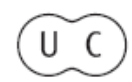




\section{REVISTA DE HISTÓRIA DAS IDEIAS 5}

\section{António Sérgio}

*

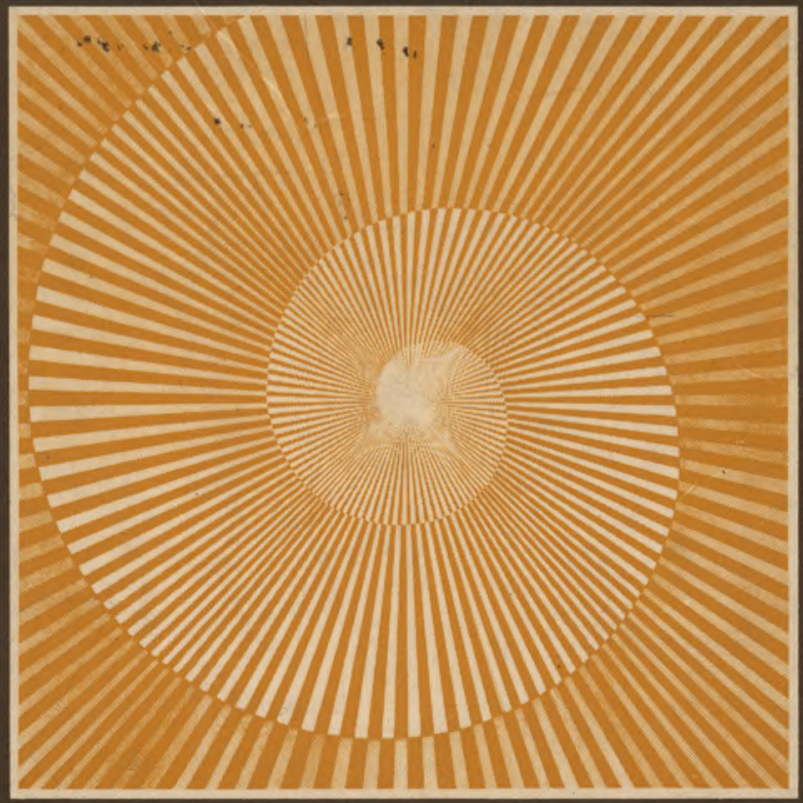

INSTITUTO DE HISTÓRIA E TEORIA DAS IDEIAS FACULDADE DE LETRAS 


\section{ITÁLIA NOS ENSAIOS DE ANTÓNIO SÉRGIO}

Não se afiguram abundantes, no conjunto das páginas de os Ensaios, as referências a Itália, à sua cultura, à sua literatura. Confirmando o que A. Campos Matos, recentemente, em imaginária entrevista, fazia dizer a Sérgio, acerca da sua intimidade, sobretudo, com a velha cultura grega e a literatura clássica francesa 0 ).

Contudo, naquela sua prática, tão cuidadosamente seguida, de uma fina atitude ensaística, consoante a Sílvio Lima aprazia acentuar $\left(^{2}\right)$, Sérgio não relegou a Itália para uma posição secundária nos Ensaios, nem deixou de a identificar com algumas das mais clarividentes ou ousadas conquistas do pensamento e que largamente pesavam na sua vastíssima formação científica, ou na sua aliciante formação humanista, oportunamente analisadas por Magalhães-Vilhena $\left({ }^{3}\right)$.

Não seria, porém, a antiga Roma, julgada pouco mais do que imitadora, e nem sempre feliz, da cultura grega $\left({ }^{4}\right)$, e definida, essencialmente, como um forte modelo de uma civilização militar e política, acaso não inteiramente do agrado de Sérgio $\left.{ }^{5}\right)$, que recolheria o seu apreço. A Itália atraía

* Faculdade de Letras da Universidade Clássica de Lisboa.

O A. Campos Matos, «Diálogo com António Sérgio», Jornal de Letras, Lisboa, II, 57, Abril de 1983.

${ }_{\left({ }^{2}\right)}$ Sílvio Lima, Ensaio sobre a essência do ensaio, 2. ${ }^{\text {a }}$ ed., Coimbra, Arménio Amado, 1964, p. 160.

$\left({ }^{3}\right)$ Vasco de Magalhães-Vilhena, António Sérgio e a Filosofia, Lisboa, Cosmos, 1960, p. 9. p. 152.

C) António Sérgio, Ensaios, vol. II, Lisboa, Seara Nova, 1929,

(5) Idem, ibidem, vol. Ill, 2. ${ }^{a}$ ed., Lisboa, Seara Nova, 1937, p. 58. 
Sérgio pelo escol que animara o seu Renascimento $\left({ }^{6}\right)$; pelo que conseguira alargar do espírito desse Renascimento $\left({ }^{7}\right)$; pelo constante senso crítico que soubera inocular na sua cultura clássica $\left(^{8}\right)$.

Mas Sérgio não menos se sentia atraído pela Itália dos tempos medievais, prenhe de uma emoção piedosa que lhe era grato acentuar $\left({ }^{9}\right)$.

São Francisco de Assis, Dante, Maquiavel ou Galileu seriam, por virtude das suas atitudes ou das suas obras, alguns dos nomes italianos que Sérgio, com maior frequência, citou nos seus Ensaios. Com eles nutrindo, talvez, algo da louvada coerência interna do seu magistério, segundo o entendia Óscar Lopes $\left({ }^{10}\right)$. Ou algo do seu pendor humanista, do seu racionalismo ou do seu próprio universalismo, a seu tempo analisados por Joel Serrão $\left({ }^{\mathrm{n}}\right)$.

Vária outra gente italiana circula nas páginas dos Ensaios. Não falta, por exemplo. D'Annunzio trazido a capítulo a propósito do simbolismo $\left({ }^{12}\right)$. Nem falta o seiscentista Marino, bizarro e impetuoso, dado por nome maior do ideal barroco, interpretado por Sérgio como um verdadeiro contrapolo de um tempo clássico. De Marino reproduzindo versos célebres e carismáticos de Murtoleide, advogados da presença da surpresa e do espanto como condições essenciais da emoção poética $\left({ }^{1 S}\right)$.

Não faltou nos Ensaios, igualmente, a lembrança de Torquato Tasso, artífice da Gerusalemme Liberata, emparceirado com Ludovico Ariosto, o cantor do Orlando Furioso, ambos passíveis, no entendimento de Sérgio, num juízo aliás comum *

(6) Idem, ibidem, p. 55.

C) Idem, ibidem, vol. II, ed. cit., pp. 19-20.

C) Idem, ibidem, vol. I, Rio de Janeiro-Porto, Anuário do

Brasil-Renascença Portuguesa, 1920, p. 38.

() Idem, ibidem, vol. Ill, ed. cit., p. 137.

(10) Óscar Lopes, Ler e Depois. Crítica e Interpretação Literária,

1, Porto, Inova, 1969, p. 222.

(n) Joel Serrão, «Para uma caracterização do ensaísmo de António Sérgio», O Tempo e o Modo, Lisboa, 47-48, Março-Abril de 1967, p. 331.

$\left({ }^{12}\right)$ António Sérgio, Ensaios, vol. I, ed. cit., p. 30. p. 117.

(13) Idem, ibidem, vol. V, 2. ${ }^{\mathrm{a}}$ ed., Lisboa, Europa-América, 1955,

Acrescente-se que os versos de Marino não foram transcritos na sua versão integral. Esta é acessível, por exemplo, em: opere Scelte di Giovan Battista Marino e dei Marinisti, vol. I, a cura di Giovanni Getto, Torino, Utet, 1963, p. 248. 


\section{Itália nos Ensaios de António Sérgio}

a uma grande parcela da crítica camoniana deste século $\left({ }^{14}\right)$, de uma condenável ausência de atitude crítica nos seus poemas $\left({ }^{15}\right)$, esquecido, porém, o facto, respeito a Ariosto, de ser o poeta italiano, seguramente, uma das fontes literárias de um Camões tão enaltecido pela sua desassombrada invectiva contra os desavindos príncipes cristãos $\left({ }^{16}\right)$.

Não falta nos Ensaios a presença do romântico D'Azeglio, na sua veste política $\left({ }^{17}\right)$. Nem faltam palavras de um Cavour identificado com os tempos da unificação italiana $\left({ }^{18}\right)$. Ou, para dias já contemporâneos, a lembrança de um Croce, vítima do fascismo $\left({ }^{19}\right)$. Não falta a alusão e o exame de conceitos enunciados por um historiador como Ferrero, parceiro possível de algumas interpretações históricas e políticas expressas por Sérgio $\left({ }^{20}\right)$.

Como se não achou afastado das páginas de os Ensaios, num ensaio por certo grato ao seu Autor, o napolitano Vico, doutrinário do «verum-factum», ordenador de leis históricas e seguro afluente no curso do génio de um Oliveira Martins $\left({ }^{21}\right)$.

Mas nome algum se avantaja aos de São Francisco de Assis, de Dante, de Maquiavel, de Galileu. Entre os quais se parece estabelecerem subtis relações e com alguns dos quais Sérgio estabeleceria relações de iniludível importância.

São Francisco de Assis desponta em um bom número de páginas dos Ensaios. Invocado na epígrafe de um combativo capítulo $\left({ }^{22}\right)$; dado como prova de uma luta por cada homem conduzida contra as tentações $\left({ }^{23}\right)$. Sobretudo, como

$\left({ }^{14}\right)$ José da Costa Miranda, «Camões / Ariosto: um confronto evidente no percurso do Orlando Furioso em Portugal», Estudos Italianos em Portugal, Lisboa, 1979-80.

$\left({ }^{15}\right)$ António Sérgio, Ensaios, vol. II, ed. cit., pp. 35-36.

(16) Idem, ibidem, vol. I, ed. cit., p. 143.

Veja-se sobre este assunto: Luciano Rossi, "Considerações sobre Ariosto e Camões», Brotéria, 11-5, Lisboa, Novembro de 1980. Ainda: José da Costa Miranda, "Ainda sobre Camões e Ariosto», Arquivos do Centro Cultural Português, XIV, Paris, 1981.

$\left({ }^{17}\right)$ António Sérgio, Ensaios, vol. III, ed. cit., p. 189.

(18) Idem, ibidem, p. 213.

(19) Idem, ibidem, p. 211-12.

(20) Idem, ibidem, vol. I, ed. cit., p. 200.

Outras referências e exame de considerações apresentadas pelo historiador italiano se encontram, por exemplo, nos vols. Ill e IV, dos Ensaios.

$C^{l}$ Idem, ibidem, vol. V, ed. cit., p. 43.

$\left.{ }^{22}\right)$ Idem, ibidem, vol. I, ed. cit., p. 307.

(23) Idem, ibidem, vol. V, ed. cit., p. 229. 
protagonista do capítulo intitulado $O$ jogral de Deus, pedaço fundamental do longo estudo dedicado ao cristianismo $\left({ }^{24}\right)$.

São Francisco seria visto por Sérgio com extrema afectuosidade, porque espelho de uma encantadora simplicidade, modelo de um comovedor humanismo poético o qual iria desembocar, segundo Sérgio, num exemplar sentimento de unidade.

Lembrava Sérgio o lirismo do cântico ao Sol. Lembrava, apoiado, por certo, nos Fioretti, a espontaneidade do sermão dos pássaros $\left({ }^{25}\right)$.

Mas Sérgio localizava em São Francisco não apenas um exemplo maior de um rejuvenescido, singelo e confiante cristianismo que o atrairia, quanto, ainda, uma origem viva de movimentos espirituais que, não só se harmonizariam com o seu magistério, quanto com uma sua caracterização de uma atitude democrática, igualitária, socialista $\left({ }^{20}\right)$.

Àquele reino de um Cristo rejuvenescido de que São Francisco se tornara luminoso ornamento, Sérgio dava como opositor o espírito de Maquiavel. A seus olhos, Cristo e Maquiavel representavam princípios inconciliáveis, defrontando-se em repetidas e contraditórias atitudes aniquiladoras, pela sua inconciliável dualidade, do homem moderno $\left({ }^{27}\right)$.

Contudo, Maquiavel irá, simultaneamente, fornecer a Sérgio considerações de extrema importância sobre a democracia. E, curiosamente, se antes Maquiavel surgia a seus olhos como o destacado adubo de uma organizada ideia nacionalista identificada, no mundo europeu, como um dos resultados políticos mais acabados do Renascimento, Maquiavel parece apresentar-se-lhe, tal como São Francisco se apresentara para o Cristianismo, como um foco renovador da ideia democrática, pela sua crença, pela sua defesa nos actos de renovação de qualquer organização, se restituída aos seus princípios essenciais $\left({ }^{28}\right)$.

Era nos Discor si sopra la prima deca di Tito Livio $\left({ }^{29}\right)$ que Sérgio achava matéria em Maquiavel para reverter ao

$\left.C^{24}\right)$ Idem, ibidem, vol. VI, Lisboa, Inquérito, 1946. Trata-se do ensaio Sobre Cristianismo e Cristãos, verdadeiros e falsos, p. 223-72.

$\left.C^{\circ}\right)$ O episódio é narrado no cap. XVI dos Fioretti.

$\left({ }^{26}\right)$ António Sérgio, Ensaios, vol. VI, ed. cit., p. 268.

$\left({ }^{27}\right)$ Idem, ibidem, vol. Ill, cd. cit., 59. Também no vol. VII, Lisboa, Europa-América, 1954, p. 210.

(28) Idem, ibidem, vol. III, ed. cit., p. 191.

(20) Valerá a pena recordar que o livro terceiro dos Discorsi tem o seguinte título: «A volere ehe una sètta 0 una republica viva lungamente, é necessario ritirarla spesso verso il suo principio». Veja-se: Niccolò Macchiavelli, Il Principe e Discorsi sopra la prima deca 
caso da democracia ameaçada pela ausência de sabedoria e de ponderação. As palavras de Maquiavel, reproduzidas e, acaso, susceptíveis, aqui ou ali, de algum ligeiro toque na sua tradução, entendia-as Sérgio por lapidares e mais do que nunca, olhando, então, ao caso português, extremamente oportunas $\left({ }^{30}\right)$.

Se em'Maquiavel encontrava Sérgio um possível inspirador para uma sua doutrinação política na senda de uma inadiável regeneração da democracia, muito embora Maquiavel se lhe apresentasse, a um tempo, como o contrário de Cristo e Cristo se lhe oferecesse como um dos mestres da Democracia $\left({ }^{31}\right)$, Sérgio localizava em um outro italiano, em Dante, o justo instante de conciliação de capacidades que se aprestava a defender, face à arrastada insensibilidade ou ao negativo dogmatismo lusitano: a compatibilidade da inteligência e da criação poética ${ }^{32}$ ). E na sequência de esse seu propósito cedo uma relação, de certeza grata ao seu espírito, era estabelecida entre Antero e Dante $\left({ }^{33}\right)$.

Mas uma outra relação era recordada, e com alguma insistência: a de Virgilio - Dante. Seguramente valorizada pelas suas preocupações de pedagogo, pela sua crença nas forças da Razão humana, que descobriria, é de crer, atrás da figura de Virgilio.

Dante, olhos postos no seu louvado Mestre, apresentava-se a Sérgio como um dos gigantes da modernidade $\left({ }^{34}\right)$. Tal como o seria Galileu, definido por fundador da ciência moderna e inquestionável criador de uma moderna mentalidade $\left(^{35}\right)$.

Galileu parece mostrar-se-lhe, se a interpretação é correcta, corno a harmonização entre o método analítico e o método dedutivo; como a harmonização entre ciência e inventiva $\left({ }^{36}\right)$. Galileu oferecia-se-lhe, ainda, como a decisiva fuga a uma física que apelidava de discursiva $\left({ }^{37}\right)$. Como se lhe

di Tito Livio, con introduzione di Giuliano Procacci e a cura di Sergio Bertelli, Milano, Feltrinelli, 1960, p. 379.

Será oportuno acrescentar-se que esse mesmo princípio do regresso a um estado de renovação ou de equilíbrio vital, passaria, igualmente, no próprio teatro de Maquiavel. Nomeadamente em Clizia, acto $V, 3$ em uma das falas de Sofronia.

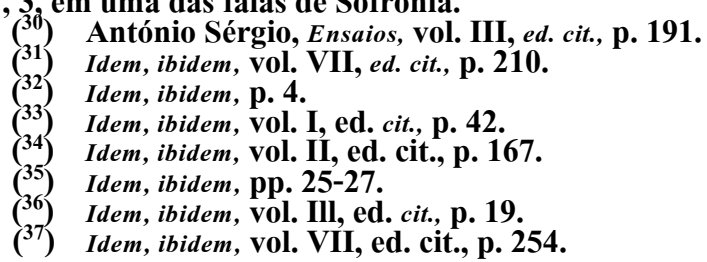




\section{Antonio Sérgio}

apresentava apto a apetrechar quem se dispusesse a desafiar uma epistemologia bergsoniana $\left({ }^{38}\right)$.

Giordano Bruno não seria esquecido, igualmente, nos Ensaios. Ombreando, pelo menos em uma não ocasional página, com Galileu. Evocando a marcha augustiante para uma ciência moderna. Recriando a presença dos arrojados «uomini nuovi» $\left.{ }^{39}\right)$. Dos quais, parece-me, e talvez deliberadamente, Campanella, o utopista de La Città del Sole, não apareceria nos Ensaios. Circunstância não secundária para uma definição do pensamento de Sérgio?

$\left.{ }^{38}\right)$ Idem, ibidem, vol. V, ed. eit., p. 179.

${ }^{(39)}$ Francesco De Sanctis, Storia della Letteratura Italiana, vol. II, a cura di Benedetto Croce, Bari, Laterza, 1949. A designação passa no cap. XIX. 